www.jmscr.igmpublication.org

Impact Factor 5.84

Index Copernicus Value: 71.58

ISSN (e)-2347-176x ISSN (p) 2455-0450

crossref DOI:_https://dx.doi.org/10.18535/jmscr/v5i12.105

Journal Of Medical Science And Clinical Research

\title{
Pattern of Intradermal Antigen Sensitivity in Patients with Nasobronchial Allergy in a Tertiary Care Centre in South Kerala
}

Authors

\author{
Raseela Karunakaran, Jose Raj R, Dinesa Prabhu V, Parvathy Santhosh
}

Department of Respiratory Medicine, Thiruvananthapuram Medical College, Kerala Corresponding Author

Parvathy Santhosh

Senior Resident, Department of Dermatology, Government Medical College, Kozhikode, Kerala Phone number: 9847153539, Email: drparvathysanthosh@gmail.com

\begin{abstract}
Introduction: The modern man is exposed to a large variety of allergens compared to his predecessors. Intradermal antigen testing provides a clinically useful method to understand the common allergens among patients. Identification of culprit allergens in patients with nasobronchial allergy shall aid in allergen avoidance and specific treatment.

Aim: To study the pattern of allergen sensitivity in patients with nasobronchial allergy.

Materials and Methods: In this retrospective study, the pattern of antigen sensitivity was analysed in 2048 patients with nasobronchial allergy who were subjected to intradermal antigen testing over a period of six years. A total of 34 antigens were tested which consisted of 16 pollen antigens, 8 dust antigens, 6 insect antigens and 4 fungal antigens.

Results: Out of 2048 patients tested, 1170 showed positive reaction. $81 \%$ of the patients had asthma, $79.6 \%$ had rhinitis, $60.6 \%$ had both, $21 \%$ had cough and $6.26 \%$ had urticaria. Among those showing positive reaction, $75 \%$ had a definite history of allergy. Maximum number of positive reaction was seen with insect antigens belonging to house dust mite (27.25\%) followed by cockroach antigen. The major dust antigen was cotton dust(25.12\%). Among pollen antigens, Cynodon dactylis showed maximum number of positive reaction (12.99\%). Aspergillus flavus and niger were the most common fungal antigens0020(both 4.44\%).

Conclusion: The commonest culprit allergens identified in this study was house dust mite followed by other insect antigens. The pattern of sensitivity may vary in different regions owing to geographical and environmental influences.

Keywords: Intradermal test, Allergens, House dust mite.
\end{abstract}

\section{Introduction}

Allergic rhinitis and asthma are manifestations of the atopic syndrome and forms the most common allergic disorder worldwide. More than 300 million of the world's population is known to suffer from one or other allergic ailments. ${ }^{(1)}$
Total surface area of the respiratory epithelium is almost $70 \mathrm{~m}^{2}$, which is continuously being exposed to inhaled particles and allergens in the ambient air. Inhaled allergens elicit immediate hypersensitivity reaction in genetically predisposed individuals. Nasobronchial allergy represents $\operatorname{IgE}$ mediated 
allergic disease of the airways. Epidemiological studies and experimental observations have suggested a close link between rhinitis and asthma, and the concept of united airway disease is a well accepted recent concept in airway allergy.

Nasobronchial allergy is triggered by environmental allergens including indoor and outdoor allergens. This type of response in airway allergy is mediated by Th2 CD4+ $\mathrm{T}$ lymphocytes and IgE. The contribution of environmental factors to development of allergic phenotype is highlighted by the hygiene hypothesis. ${ }^{(2)}$ The united airway hypothesis points to the impact of upper airway disease on the lower airway physiology.

The term allergy is used when an antigen which is not harmful in itself causes an immune response and reaction which gives rise to symptoms and disease in a few individuals only. An antigen capable of eliciting an allergic response is termed allergen. When an allergen reacts with IgE antibody attached to the surface of mast cell, the cell degranulates and liberates histamine and other mediators. This type of reaction occurs within minutes and is the immediate phase reaction of Type 1 hypersensitivity. This is followed by a late phase reaction mediated by cytokines, eosinophils and newly synthesised mediators.

Due to the changing lifestyle and frequent movement of population, the modern man is exposed to a much larger variety of allergens compared to his predecessors. The type of allergens and the pattern of incidence is variable, depending on the geographical area and population, and the seasons of the year. Western style housing favours greater exposure to indoor allergens, especially in infants and children which has been known to be the primary cause of rise in asthma incidence. ${ }^{(2)}$ With rapid strides in technology, more and more sophisticated methods of characterisation of allergens are becoming available to us.

Identification of culprit allergens in patients with nasobronchial allergy shall aid in allergen avoidance measures and specific allergen immunotherapy. Studies done in different parts of India show varying patterns of allergen sensitivity. This may be attributed to geographical and environmental influences. There are few published studies on allergen sensitivity testing in Kerala.

\section{Materials and Methods}

This study was a retrospective analysis conducted in the Department of Respiratory Medicine in a tertiary care centre in south Kerala. After obtaining ethical clearance, the case sheets of patients subjected to intradermal antigen testing during a period of six years from 1997-2002 were analysed.

All the patients reporting to the outpatient department of Respiratory Medicine Department with symptoms of nasobronchial allergy were included in the study. Patients on systemic corticosteroids and other immunosupressants or any other drug that could interfere with the results of the study were excluded from the study. Patients were asked to stop antihistamines 48 hours prior to testing. A detailed history of patients with regard to symptoms in relation to exposure to allergens was taken. Details regarding duration of illness, precipitating or aggravating factors, family history of allergic diseases and treatment history were noted.

Intradermal antigen testing was performed after obtaining informed written consent. Aqueous allergens in dilutions ranging from 1:500 to 1:5000 w/v was loaded in a $1 \mathrm{ml}$ syringe with $26-27 \mathrm{G}$ needle and $0.02 \mathrm{ml}$ of it was carefully injected intradermally over the volar aspect of the upper limb at intervals of $2-2.5 \mathrm{~cm}$. The injection has to be very superficial and shallow enough to enable formation of a wheal that can be sharply defined so that its size can be measured easily. The intradermal test site was observed and reading recorded at the end of 20 minutes. Results were interpreted using Shivpuri's criteria. (Table 1$)^{(3)}$ A reading of $2+$ or more was taken as positive. A total of 34 antigens were tested which included 16 types of pollen, 4 types of fungi, 8 types of dust and 6 types of insects. Buffered saline was used as negative control to rule out dermographism. The total number of patients tested during the period of 6 years was 2048 . 


\section{Results}

The total number of patients tested was 2048 of which 1113 were females and 935 were males. 1170 patients $(57.13 \%)$ showed a positive reaction to intradermal testing with one or more allergens which included 636 females and 534 males. Among the study group, $81 \%$ patients had asthma, $79.6 \%$ patients had allergic rhinitis, $60.6 \%$ patients had both, $21 \%$ patients had cough and $6.26 \%$ patients had urticaria. Among the patients who showed a positive skin test reaction, $75 \%$ had a definite history of precipitation of symptoms on exposure to allergens.

Among the four groups of antigens tested, insect antigens showed the maximum number of positive reactions, the highest being house dust mite $(27.25 \%)$. The major dust antigen was cotton dust (25.12\%). Among pollen antigens, Cynodon dactylis showed maximum number of positive reaction (12.99\%), while Aspergillus flavus and niger were the most common fungal antigens (both $4.44 \%$ ). (Tables 2-5)

Table 1- Shivpuri's criteria (1962) of grading positive skin test

\begin{tabular}{|c|c|c|}
\hline & Symbol & Intradermal test \\
\hline Negative & - & $\begin{array}{c}\mathrm{W}=\text { same as negative control }(4-5 \mathrm{~mm}), \\
\text { erythema nil }\end{array}$ \\
\hline Doubtful & $+/-$ & $\mathrm{W}<1+$ \\
\hline $1+$ & + & $\begin{array}{c}\mathrm{W}=5 \mathrm{~mm} \text { more than negative control or twice } \\
\text { of negative control }\end{array}$ \\
\hline $2+$ & ++ & $\mathrm{W}=8 \mathrm{~mm}$ greater than negative control \\
\hline $3+$ & +++ & $\begin{array}{c}\mathrm{W}=11 \mathrm{~mm} \text { more than negative control with or } \\
\text { without one or two ps }\end{array}$ \\
\hline $4+$ & ++++ & $\begin{array}{c}\mathrm{W}=14 \mathrm{~mm} \text { more than negative control with } \\
\text { several } \mathrm{p}\end{array}$ \\
\hline
\end{tabular}

Table 2 - Insect antigens

\begin{tabular}{|l|c|c|c|}
\hline Sl no & Antigen tested & Number positive & Percentage \\
\hline 1 & House dust mite & 322 & 27.52 \\
\hline 2 & Cockroach female & 294 & 25.12 \\
\hline 3 & Cockroach male & 281 & 24.01 \\
\hline 4 & Housefly & 276 & 15.04 \\
\hline 5 & Ant & 137 & 11.70 \\
\hline 6 & Mosquito & 131 & 11.19 \\
\hline
\end{tabular}

Table 3- Dust antigens

\begin{tabular}{|l|c|c|c|}
\hline Sl no & Antigen tested & Number positive & Percentage \\
\hline 1 & Cotton dust & 294 & 25.12 \\
\hline 2 & Rice grain dust & 293 & 25.04 \\
\hline 3 & House dust whole & 268 & 22.89 \\
\hline 4 & Wheat grain dust & 255 & 21.79 \\
\hline 5 & Ration shop dust & 243 & 20.77 \\
\hline 6 & Hay dust & 193 & 16.51 \\
\hline 7 & Grocery dust & 186 & 15.9 \\
\hline 8 & Paper dust & 95 & 8.12 \\
\hline
\end{tabular}

Table 4- Pollen antigens

\begin{tabular}{|l|c|c|c|}
\hline S1 no & Antigen tested & Number positive & Percentage \\
\hline 1 & Cynodon dactylis & 152 & 12.99 \\
\hline 2 & Heteropogon contortus & 117 & 10 \\
\hline 3 & Sweitenia mahogany & 103 & 8.80 \\
\hline 4 & Oreodoxa sp. & 102 & 8.71 \\
\hline 5 & Carica papaya & 66 & 5.64 \\
\hline 6 & Eucalyptus sp & 66 & 5.64 \\
\hline 7 & Cocos nucifera & 56 & 4.79 \\
\hline 8 & Amaranthus sp & 53 & 4.42 \\
\hline 9 & Peltophorum sp. & 51 & 4.35 \\
\hline 10 & Azadiracta indica & 47 & 4.01 \\
\hline 11 & Casuarinas sp. & 45 & 3.84 \\
\hline 12 & Cassia occidentalis & 42 & 3.59 \\
\hline 13 & Albizia lebbek & 35 & 2.99 \\
\hline 14 & Phoenix dactylifera & 32 & 2.73 \\
\hline 15 & Cassia siamea & 29 & 2.49 \\
\hline 16 & Areca catechu & 19 & 1.62 \\
\hline
\end{tabular}

Table 5- Fungal antigens

\begin{tabular}{|l|l|l|l|}
\hline Sl no & Antigen tested & Number positive & Percentage \\
\hline 1 & Aspergillus flavus & 52 & 4.44 \\
\hline 2 & Aspergillus niger & 52 & 4.44 \\
\hline 3 & Candida albicans & 40 & 3.41 \\
\hline 4 & Aspergillus fumigatus & 33 & 2.82 \\
\hline
\end{tabular}

\section{Discussion}

In our study, the commonest group of offending allergens was insects, followed by dust, pollen and fungal antigens respectively. Similar findings have been reported by Chogtu et al in Karnataka ${ }^{(4)}$. A few other studies also have reported insects as the most common offending allergens in patients with nasobronchial allergy ${ }^{(5-7)}$ Another study with a relatively smaller sample size (50 subjects) has reported House dust mite as the commonest allergen $(78 \%)$ followed by dust and other insects ${ }^{(8)}$.

In our study, the most frequent individual offending allergen was house dust mite $(27.25 \%)$ which is consistent with the findings of Balaban et $\mathrm{al}^{(9)}$. House dust mite is known to be a common cause of allergy worldwide ${ }^{(10)}$. In the study by Kumar et al , the most frequent individual allergen was moth ${ }^{(7)}$. In a study done in Lucknow by Prasad $\mathrm{R}$ et al, the most common allergen was found to be the pollen of Amaranthus spinosus $(39.58 \%)^{(6)}$. Chogtu et al, in a study conducted in south India, which mostly included patients from Karnataka, reported the most common offending allergen to be rice grain dust ${ }^{(4)}$.

The most common insect allergen in our study was house dust mite $(27.52 \%)$ followed by cockroach female $(25.12 \%)$ and cockroach male $(24.01 \%)$. Mishra VD et al also reported similar findings (11) However, various studies conducted in different 
parts of the world have reported cockroach to be the most common insect allergen ${ }^{(8,12,13)}$ Other studies have reported moth as the most common insect allergen $^{(5,7)}$.

Among pollen antigens, Cynodon dactylis showed the maximum number of positive reactions (12.99\%) followed by Heteropogon (10\%), Mahogany $(8.8 \%)$ and Oreodoxa $(8.71 \%)$ in our study. In the study by Kumar et al, the most common allergen among pollens was Amaranthus spinosus (35.4\%), Argemone Mexicana (22.9\%) and Adhathoda vasica $(18.5 \%)^{(7)}$. Prosopis, Argemone and Eucalyptus were the three most common pollen allergens observed by Chogtu et $\mathrm{al}^{(4)}$. Balaban et al in their study conducted on 2254 patients in Bosnia, reported weed pollen as the most frequent pollen allergen, among which ragweed was the commonest. ${ }^{(9)}$ The wide disparity in the findings of various studies may be due to differences in the indigenous plant population at the places of study.

In our study, the major dust allergen was cotton dust $(25.12 \%)$ followed by rice grain dust $(25.04 \%)$, house dust whole $(22.89 \%)$, wheat grain dust $(21.79 \%)$ and ration shop dust (20.77\%). Chogtu et al in Karnataka reported the most common individual allergen to be rice grain dust although the most common allergen group was insects ${ }^{(4)}$.

Our observation that the most common fungal allergens were Aspergillus flavus and Aspergillus niger ( $4.44 \%$ each) was supported by the findings of Chogtu et al, who also reported Aspergillus flavus to be the most common fungal allergen. ${ }^{(4)}$ However there are studies reporting Aspergillus fumigatus to be more common ${ }^{(6,8)}$. Jerath et al in their study conducted in Punjab, tested skin sensitivity exclusively to fungal antigens and concluded that Cladrosporium herbarum was the most common fungal allergen (11\%), followed by Alternaria $(10 \%)^{(14)}$. A study on 180 poultry workers in Jabalpur showed a predominance of sensitivity to Aspergillus niger ${ }^{(15)}$. This again highlights the regional variation in the prevalence and sensitivity pattern of allergens in different patient populations. The evidence that allergens found inside houses are an important cause of perennial rhinitis and asthma, as observed in our study as well as previous studies, underscores the fact that early exposure to antigens is an important factor for sensitisation and development of hypersensitivity. Effective control strategies should be tailored to individual allergens, flexible to suit individual needs and also must be cost effective. In patients in whom symptoms persist despite specific allergen avoidance measures, and are not controlled by medications, there is a definite role for specific immunotherapy using allergen extracts after identification of the specific allergen by skin prick test. ${ }^{(15)}$

Intradermal skin testing is a globally accepted modality to detect sensitivity to allergens. Allergen avoidance is a measure recommended in asthma patients. The ambient air contains a large number of allergens and particulate matter which cannot be fully eliminated from the inspired air. A normal healthy adult takes in around 10,000 litres of air per day. One cubic metre of air contains around 50,000 fungal spores which may increase in number seasonally and based on climatic conditions. Hygiene hypothesis makes compelling evidence that the rise in allergies is an inadvertent consequence of the accomplishment of domestic hygiene in reducing the rate of infections in childhood by avoidance measures. Western style housing, unventilated living rooms, and practice of keeping children indoors may expose them to more indoor allergens leading to sensitisation and allergic disease. One study showed that endotoxin levels in dust samples from homes were protective against asthma in children ${ }^{(16)}$. Another cohort study found that lower prevalence of asthma and atopy was seen in children living on farms with exposure to a variety of environmental microorganisms ${ }^{(17)}$.

Specific immunotherapy has been found to be a successful modality of treatment in patients with a definite causal association with an allergen identified by allergen sensitivity testing. The drawback is the long duration of treatment required for success of immunotherapy. This modality of treatment is likely to stimulate the innate immune receptors to trigger adaptive immune response to serially increasing concentration of therapeutic 
allergens administered. In patients with intractable allergic symptoms not responding to standard medical therapy, immunotherapy is a useful adjunct. Future research in the field of immunotherapy may be hopeful in the field of asthma and other allergic disorders.

\section{Limitations}

Food allergen testing was not done. Also, since the study was conducted at a tertiary care centre, there is a possibility of referral bias.

\section{Conclusion}

The most common culprit allergen identified in patients with nasobronchial allergy was house dust mite, followed by cockroach female, cotton dust, rice grain dust and cockroach male. The findings of our study may prove useful for allergen avoidance measures and specific immunotherapy in patients with intractable symptoms in our population.

\section{Source of support- Nil \\ Conflict of Interest- Nil}

\section{References}

1. Singh AB, Mathur C. An aerobiological perspective in allergy and asthma. Asia Pac Allergy. 2012;2(3):210-22.

2. Woodruff PG, Bhakta NR, Fahy JV. Asthma: pathogenesis and phenotypes. In: Broaddus VC, Mason RJ, Ernest JD, King TE, Lazarus SC, Murray JF, Nadel JA, Slutsky AS, Gotway MB. Murray and Nadel's textbook of respiratory medicine. In: 6th ed. India: Elsivier; 2016: 713-30.

3. Shivpuri DN. Comparative evaluation of the sensitivity of common methods of diagnostic antigen tests in patients with respiratory allergy. Indian J Chest Dis. 1962;4:102-8.

4. Chogtu B, Magaji N, Magazine R, Acharya PR. Pattern of Allergen Sensitivity among Patients with Bronchial Asthma and/or Allergic Rhinosinusitis in a Tertiary Care Centre of Southern India. J Clin Diagn Res. 2017;11(8):OC01-OC04.
5. Patel A, Choudhary S. Prevalence of Allergen Sensitivity in Nasobronchial Allergy in Gujarat, India. Natl J Med Res. 2012;2:431-4.

6. Prasad R, Verma SK, Dua R, Kant S, Kushwaha RA., Agarwal SP. A study of skin sensitivity to various allergens by skin prick test in patients of nasobronchial allergy. Lung India Off Organ Indian Chest Soc. 2009;26(3):70-3.

7. Kumar R, Sharan N, Kumar M, Bisht I, Gaur S. Pattern of skin sensitivity to various aeroallergens in patients of bronchial asthma and/or allergic rhinitis in India. Indian $\mathbf{J}$ Allergy Asthma Immunol. 2012: 1;26.

8. Agrawal RL, Chandra A, Jain S, Agrawal G, Snehlata. Identification of common allergens by skin prick test associated with united airway disease in Allahabad, Uttar Pradesh, India. Indian J Allergy Asthma Immunol. 2008;22(1):7-13.

9. Balaban J, Bijelic $\mathrm{R}$, Milicevic $\mathrm{S}$. Hypersensitivity to aeroallergens in patients with nasobronchial allergy. Med Arch Sarajevo Bosnia Herzeg. 2014;68(2):86-9.

10. Milián E, Díaz AM. Allergy to house dust mites and asthma. P R Health Sci J. 2004;23(1):47-57.

11. Mishra DV, Mahmood T, Mishra JK. Identification of common allergens for united airway disease by skin prick test. Indian J Allergy Asthma Immunol. 2016;30(2):76-9.

12. Sarinho ECS, Mariano J, Sarinho SW, Medeiros D, Rizzo JA, Almerinda R S, et al. Sensitisation to aeroallergens among asthmatic and non-asthmatic adolescents living in a poor region in the Northeast of Brazil. Allergol Immunopathol (Madr). 2009;37(5):239-43.

13. Sam CK, Soon SC, Liam CK, Padmaja K, Cheng HM. An investigation of aeroallergens affecting urban Malaysian asthmatics. Asian Pac J Allergy Immunol. 1998 Mar;16(1):17-20. 
14. Jerath VP, Sood M, Nischal R. Prevalance of skin reactivity to fungal antigens in patients of nasobronchial allergy of Jalandhar and neighbouring area in Punjab. Indian $\mathbf{J}$ Allergy Asthma Immunol. 2012;26(2):73-6.

15. Verma KS, Shrivastava P, Dey M. Skin prick test to common air borne fungi on poultry workers.Indian J Allergy Asthma Immunol. 2011;25(2):79-83.

16. Carlsten C, Ferguson A, Dimich-Ward H, Chan H, DyBuncio A, Rousseau R, et al. Association between endotoxin and mite allergen exposure with asthma and specific sensitization at age 7 in high-risk children. Pediatr Allergy Immunol Off Publ Eur Soc Pediatr Allergy Immunol. 2011 May;22(3): 320-6.

17. Ege MJ, Mayer M, Normand A-C, Genuneit $\mathrm{J}$, Cookson WOCM, Braun-Fahrländer C, et al. Exposure to environmental microorganisms and childhood asthma. $\mathrm{N}$ Engl J Med. 2011 Feb 24;364(8):701-9. 